\title{
Las Casas y los lascasianos ${ }^{\mathrm{A}}$
}

\section{Germán Colmenares}

\section{Introducción: Las Casas, la "Leyenda Negra" y la "cuestión indígena"}

Fray Bartolomé de las Casas fue uno de los pocos testigos honestos de una de las más grandes tragedias de la historia humana: la catástrofe demográfica indígena del siglo XVI en América. La celebridad de Las Casas en toda Europa estuvo asociada a un debate ideológico que enfrentaba a los herederos de la idea medieval del Imperio cristiano con nuevas fuerzas sociales cuya ideología pugnaba por expresarse en disidencias de tipo religioso. Que su obra haya sido utilizada por los enemigos del Imperio, desde los protestantes de los Países Bajos, que conocieron la devastación de los "tercios" españoles, a la Inglaterra del siglo XVIII, que disputaba a España los restos de sus dominios, hace parte necesariamente de la historia de las ideologías.

¿Cómo plantear modernamente la controversia sobre la "cuestión indígena"? Sí, por ejemplo, se admite el hecho fundamental de la catástrofe, pero pretende retomarse la cuestión al nivel en que se discutía en el siglo XVI, es decir reduciéndola a una simple "cuestión moral", se corre el riesgo de perder de vista la verdadera dimensión del problema y de sus implicaciones. Un proceso histórico complejo no está movido por una voluntad personal, a la que pueda atribuirse una responsabilidad moral. Calificar de moralmente "buena" o "mala" la conquista española obedece a la deformación ideológica que ve constantemente en la historia la sobreimpresión de voluntades individuales. Este expediente es tan corriente todavía que muchos historiadores se han sentido obligados a asegurarnos que, desde el punto de vista moral (del siglo XVI, por supuesto), la obra de España en América es irreprochable. Para ello han escudriñado todos los alegatos (de tipo moral o teológico) que puedan contribuir a dar una idea de la excelencia de la ideología que se elaboraba en España con respecto a los indígenas. Lo que realmente ocurrió en América no parece tener demasiada importancia. Se supone que el mero alegato teológico y moral debió influir de alguna manera en el comportamiento de los pobladores europeos y con seguridad en la política que se traducía en las llamadas "Leyes de Indias".

Otros prefieren negar de plano la magnitud del desastre demográfico. De esta manera se despoja a un personaje como Las Casas de toda razón de ser histórica y se lo convierte en un simple caso patológico.

A En Estravagario, revista cultural del periódico El Pueblo, n. ${ }^{\circ}$ 38, 12 de octubre de 1975, 3 y ss. Copio a partir de una fotocopia que se encuentra en los papeles en que se apoya esta recopilación. 
El problema, sin embargo, no consiste, en seguir el discurso de Las Casas y dejarnos persuadir por él u oponerle resistencias nacidas en alguna forma de "patriotismo". La "cuestión indígena" no es en nuestros días una cuestión moral o teológica, sino un problema científico. Y, a su vez, la personalidad de Fray Bartolomé de las Casas no es un asunto, científico o pseudocientífico, definible en vagos términos psicoanalíticos, sino un problema que se inserta en los umbrales de la historia, precisamente el umbral de las relaciones entre una personalidad individual y un fenómeno colectivo.

Por eso no podemos rescatar la individualidad, ni siquiera comprenderla, haciendo abstracción del fenómeno colectivo. Diciendo, por ejemplo, "no importa que Las Casas se haya equivocado en la cuenta de algunos millones más o menos de indígenas. Sobre una cuestión tan dudosa el historiador no puede emitir juicio alguno. Pero, en cambio, es indudable que el dominico fue una personalidad excepcional". Con un razonamiento semejante no hacemos otra cosa que negar la historias para rendir un pobre tributo al "héroe" y al "ser excepcional". Pero ¿qué importancia tendría entonces rendir homenajes a un hombre que nació hace 500 años, a un personaje que podría relegarse en la falange de otros cronistas más verídicos y de mayor talento literario, a un ser emocionalmente desequilibrado, que no podía soportar los hechos más corrientes de la vida y una cierta rudeza de su propio siglo sin lanzar imprecaciones a cada paso?

Pero aun para los escépticos, en ese umbral problemático entre el hecho individual y los fenómenos colectivos, entre la biografía y la historia, Fray Bartolomé de las Casas es como un signo de interrogación.

\section{Los testimonios sobre el desastre}

Las Casas hace posible recobrar la historia real y colectiva a partir de su testimonio individual. Pero su figura, su palabra, carecen de sentido histórico si se pretende hacer de él un personaje humanitario, interesado por la muerte de un puñado de indígenas que se consumían ante sus ojos. No. Las casas representa en el momento de la conquista, la lucidez desesperada. Su información, según la cual en la Isla de Santo Domingo había un millón 800 mil naturales, era a todas luces, más segura que la de sus detractores. Pues hasta ahora [esos testimonios] no han atraído la atención de las academias, que dedican a los fastos recordatorios todos aquellos documentos problemáticos en su manejo, pero objetivos, que le dan la razón a Las Casas. Me refiero a las "visitas de la tierra" practicadas en los siglos XVI y XVII (más raramente en el siglo XVIII), a los documentos que registran el pago de los tributos o a las afirmaciones de los cronistas de las cuales pueda comprobarse que se derivan de "visitas" o de "repartimientos" de encomiendas.

Las visitas, utilizadas de manera sistemática por primera vez en Colombia por Juan Friede, reflejan sin lugar a dudas el ciclo entero de la catástrofe. Lo que Las Ca- 
sas había presenciado en el laboratorio antillano de la ocupación española se repite, en proporciones diferentes pero con las mismas características, en toda la América continental. En presencia de estos testimonios, fríamente burocráticos, no cabe la ambigüedad. Ellos dan cuenta, a lo largo de más de un siglo, del desmoronamiento de los pueblos indígenas con ratas de un descenso demográfico tan elevadas que solo podían soportar masas humanas originalmente muy densas.

\section{El contexto político}

A pesar de estos testimonios repetidos en millares de documentos, la historiografía oficial sigue repitiendo - muy probablemente por inadvertencia - que la encomienda constituye el más grande monumento de previsión y ciencia legislativa... y será siempre "timbre del honor... y la gloria de España". O pretende que el resumen de miles de cédulas reales que se enviaron a las Indias (conocido como Recopilación de leyes de Indias) constituye otro monumento a la "previsión" y al espíritu de justicia que animaba a la monarquía española. Se lamenta, eso sí, que ese código admirable no se cumpliera. Pero ¿cómo podía cumplirse si cada cédula no era otra cosa que la comprobación oficial ex post facto de un abuso? Desde este punto de vista resulta que la Recopilación no es sino un catálogo abreviado de todas las violaciones prácticas del derecho de gentes. Y todas estas inanes apologías ni siquiera perciben que las cédulas reales era una tenue herramienta política para contrarrestar los excesos de los españoles - americanos, envanecidos con un poder que los incitaba a enfrentarse a la Corona. Por esta razón, casi todos los testimonios que poseemos en favor de los indios proceden, unas veces, de funcionarios celosos de las prerrogativas reales, otras, de comunidades eclesiásticas que no tuvieron acceso a los privilegios de la encomienda pero que requerían mano de obra para sus empresas terrenas.

Ahora bien, casi nunca, en el curso de tres siglos, el Estado Español tuvo en América la fuerza suficiente para contrarrestar la influencia de poderes locales y ni siquiera para evitar que sus propios funcionarios entraran en colisión con estos poderes. La lucha contra los encomenderos, por ejemplo, no tuvo otro resultado que abrir paso a los abusos de los terratenientes, curas y corregidores. Los cabildos de las ciudades españolas —esta institución que se elogia siempre, como las leyes de indias, por su aspecto formal-, fueron asambleas celosamente oligárquicas y que tradujeron sucesivamente los intereses familiares y parroquiales de los encomenderos, terratenientes, mineros y comerciantes.

Es en este contexto político que debe situarse la figura de Las Casas. Su importancia no reside en una posición moral sino en una pasión política. Nadie ha pensado seriamente en hacer un santo de Fray Bartolomé, que se sepa. Pero en cambio su obra ha estado siempre en el centro de una controversia política. Política, no solo por cuanto inspiró unas directrices pasajeras del Emperador respecto a las encomiendas y al 
tratamiento de los indios, sino por cuanto previó los resultados fatales de un sistema de dominación. Su testimonio posee características de modernidad porque Las Casas escapaba de los estrechos moldes ideológicos de su época para encarar la realidad.

En sus alegatos, las justificaciones ideológicas de la evangelización de los indios o del papel mesiánico de la monarquía española pasan a un segundo plano frente a la necesidad de conjurar una catástrofe sin precedentes. Por eso busca, por todos los medios a su alcance, desarmar un sistema político mortífero, que no solo amenazaba a los pueblos indígenas, sino que constituía un desafió al poder mismo de la monarquía española. En el momento en que se fortalecían en Europa los Estados nacionales en torno al principio dinástico, Las Casas echa mano de las prerrogativas reales para enfrentar la insolencia de los nuevos amos de América. Y como se sabe, lo consigue, al menos momentáneamente.

\section{García de Valverde y las "visitas de la tierra" de 1560-1570}

Desechados los aspectos morales, se comprende mejor el sentido con que se aplicaron las "Leyes Nuevas" y la acción de algunos "Lascasianos" en distintas regiones de América. Ellos, como el mismo Las Casas, enfrentaron poderes políticos e intereses creados desenmascarando la ideología que los encubría. No era el alma del indígena lo que se buscaba, sino su trabajo; ni la cristianización de las tribus, sino sus tierras; ni la conversión de su conciencia pagana, sino sus idolillos de oro.

De manera característica, el fiscal de la Audiencia en tiempos de Venero de Leyva, y primer defensor laico de los indios de Nueva Granada, García de Valverde, reivindicaba la soberanía del Estado español:

“...toda persona ha de ser sujeto a su príncipe e rey e señor natural”; y entendía por "toda persona" a los encomenderos americanos que rehusaban participar a la Corona de los tributos que arrancaban a los indios.

El testimonio de Las Casas no era una abstracción moral o el fruto desorbitado de una imaginación enferma. El funcionario García de Valverde podía muy bien comparar, en los archivos de la Audiencia o de la Gobernación de Popayán, las cifras que arrojaban los "repartimientos" iniciales y aun los recuentos de tributarios que se habían efectuado antes de él. Comparando, por ejemplo, las cifras de una vista efectuada en 1550, con la que practicara en 1561 el oidor Ángulo de Castejón, reprochó a este que hubiera inflado la población de indígenas tributarios para obtener de cada comunidad un tributo superior a sus fuerzas.

García Valverde encarnaba muy bien el espíritu del gobierno en la década de 1560-1570, en la cual se realizaron sistemáticamente "visitas de la tierra" dentro de las prescripciones de las "Leyes Nuevas". Estos fueron los primeros intentos en la 
Nueva Granada de "normalizar" institucionalmente los resultados de la conquista y de poner coto a los abusos de una casta que amenazaba con romper el equilibrio colonial. Este equilibrio consistía en el reconocimiento de privilegios locales de los cabildos y aun el otorgamiento de premios excepcionales a los "beneméritos", pero mediante un reconocimiento de la soberanía del Estado español.

Las "visitas de la tierra" perseguían, en ese primer momento, hacer un inventario de los recursos de las economías indígenas y ponerlas bajo la protección del Estado. La intención era que los oidores recorrieran, por turnos anuales, el territorio sujeto a la jurisdicción de la Audiencia y visitaran todos los "repartimientos" y pueblos de indios. Los caciques, los curas doctrineros y los mismos encomenderos debían responder a un cuestionario en el que se incluían preguntas sobre la organización social indígena original, su producción económica, los adelantos y los obstáculos en la labor de los doctrineros y el trato que recibían los indígenas de parte de sus encomenderos. Luego se hacía un recuento de los indígenas en capacidad de tributar y se fijaba una "tasa" de los tributos.

Los primeros intentos de establecer un tributo que no excediera la fuerza de los indios, tal como lo ordenaban las "Leyes Nuevas", originaron protestas y tácticas dilatorias de cabildos y encomenderos. Alegatos, pleitos y reticencias sin fin, cuando no amenazas abiertas o coacciones sutiles contra los visitadores, todo se movilizó para impedir que el Estado afirmara uno de sus más elementales atributos: el poder de imponer gravámenes a sus vasallos.

En rigor, esta y otras medidas de las visitas del periodo 1560-1570, no eran sino la aplicación tardía de las "Leyes Nuevas", uno de los triunfos de Las Casas. Por ejemplo, García de Valverde recomendaba en 1562 que se cumplieran sus preceptos más importantes: la abolición del servicio personal y la prohibición de las "entradas" de españoles a los pueblos de indios. En la Nueva Granada esto significaba que, por primera vez, el Estado intervenía la "empresa privada" de los encomenderos.

Los "servicios personales" no equivalían formalmente a la esclavitud. Se derivaban de las relaciones "personalizadas" que imponía la encomienda, es decir, de la privación de un salario que mediatizara estas relaciones. A pesar de los esfuerzos de los visitadores nunca fue posible desarraigarlos y así pudieron evolucionar libremente en otras formas de dependencia dentro del sistema agrario de la hacienda y aun en el seno del mismo sistema capitalista.

Las "entradas" servían igualmente para reforzar el sistema señorial. Las nuevas ciudades alimentaban con los tributos de los indios toda una clase social que pagaba soldados a "su costa" y que organizaba periódicamente expediciones que irrumpían en medio de pueblos pacíficos para aumentar el botín de la conquista. Los encomenderos mantenían esta clientela con el fruto de sus encomiendas y la alojaban en sus casas, realzando su prestigio con el número de estos servidores ociosos. 
Finalmente, García de Valverde, como Las Casas, comprendía la fragilidad de un sistema complejo de relaciones entre los indígenas y su medio, tanto como la delicada estructura de organización social. Para él, una de las mayores tragedias de los indios consistía en la descomposición social que afectaba no solo a un sistema familiar y de jerarquías, sino aun a los patrones tradicionales de conducta. La labor del Estado debía consistir nada menos que en volver a reconstruir todo ese sistema de referencias sin el cual la vida social es imposible. Y el primer paso debía consistir en la abolición de todo un sistema montado sobre la base de la explotación de los pueblos indígenas.

\section{El significado de la política "indigenista"}

Una simplificación ideológica excesiva, que se operó en la ruptura republicana del siglo XIX, ha hecho perder de vista los términos políticos reales en los cuales se inscribía el problema indígena. Dentro de su deformación republicana, este problema queda reducido a la cuestión mucho más general de la dependencia con respecto a la metrópoli. De esta manera puede describirse un enfrentamiento entre "españoles" e "indígenas", en el cual se identifica a los "españoles" con conquistadores que desaparecen misteriosamente de la escena para ser reemplazados por funcionarios de la monarquía.

La realidad es más compleja: los conquistadores o sus descendientes no desaparecieron tan calladamente y muchos funcionarios españoles no juegan el papel de villanos que se les asigna en los manuales escolares. En realidad ellos fueron los ejecutores de una política "indigenista" que se ejercía, más que en favor de los indios, en contra de los españoles americanos. Y no se trataba, en ningún caso, de corregir el comportamiento individual de los encomenderos, sino de contrarrestar los efectos de un sistema de poder que tenía como centro el cabildo local.

Con todo, la política "indigenista" de la Corona española, tal como se revela en el texto de las "Leyes Nuevas", de innumerables cédulas [reales] casuistas y aun de la acción de los Lascasianos como el obispo Juan del Valle o de García de Velarde, estaba condenada al fracaso. Y no por culpa de los Lascasianos o de los funcionarios de la Corona sino porque a cada paso tenía que transigirse con los intereses económicos coloniales. Si por un lado se buscaba someter las pretensiones políticas desmesuradas y amenazadoras de grupos locales de encomenderos, terratenientes y mineros, por el otro lado se tenía que capitular ante el hecho de que la mano de obra indígena, cada vez más escasa, era indispensable para las labores de minas y estancias. El mismo García de Velarde se vio obligado, en 1570, cuando las presiones de los españoles americanos habían hecho refluir la intención original de las "Leyes Nuevas", a sancionar (como oidor-visitador de la Audiencia de Quito) la costumbre de emplear a los indígenas en las minas de Popayán. A partir de este año también, tanto el virrey del 
Perú como la Audiencia de la Nueva Granada, autorizaron mediante ordenanzas el trabajo de los indios en las minas.

A finales del siglo XVI la población indígena representaba menos del 10\% de la que había sido su cantidad original. Con esta disminución asombrosa desapareció uno de los factores de poder más importantes de los encomenderos. El debilitamiento del sistema hizo posible que, a comienzos del siglo XVII se sustituyera el monopolio de la mano de obra por el "concertaje", al cual tenían acceso los propietarios no encomenderos. La emergencia de estos simples propietarios obligó a concentrar la fuerza de trabajo en poblados dotados de resguardos de donde podían sacarse indígenas periódicamente para atender a los conciertos. El otorgamiento de resguardos no fue, como se ha pretendido, una "reforma agraria" sino, a lo sumo, una modificación del régimen de servidumbre indígena. De otro lado, se buscaba incrementar el producto del tributo, en el cual la Corona tenía ya una participación cierta, introduciendo un régimen de salario entre los indios. No fue, pues, la política "indigenista" la que transformó las relaciones de producción, sino los cambios que se operaron en las fuerzas productivas. La letra de la ley nunca poseyó la virtualidad de modificar un sistema que se apoyaba en condiciones muy concretas de dominación. Instituciones más favorables como el concierto o los resguardos ni siquiera aparecieron como una respuesta para preservar las comunidades indígenas sino para generalizar el empleo de la mano de obra disponible.

El ciclo entero de la extinción de los pueblos indígenas se prolongó hasta mediados del siglo XVII. El experimento español había sido desastroso y desembocó en una centuria entera de depresión económica y política. La suerte de estas naciones, con sus peculiares estructuras económicas y sociales (mucho más fundamentales que la mera dependencia política de España) y un sistema ideológico que las justificaba, quedaba sellada desde entonces. La conquista había generado un sistema de explotación irracional que iba a persistir más allá de sus propios fracasos, conformando estructuras de dominación y patrones mentales de evolución muy lenta.

¿Cómo medir entonces el alcance y la influencia lascasiana? La historia intelectual suele encadenar coincidencias verbales o establecer nexos entre las formulaciones similares de unas cuantas ideas esenciales.

El problema de Las Casas, y de algunos otros que actuaron en el mismo sentido, no tiene este significado puramente académico. Su obra, más que sus ideas de raigambre teológica y moral, ilustra una lucha política personal contra un sistema y hace parte de una historia colectiva.

Naturalmente, no me refiero aquí a una historia colectiva que busca exaltar una pretendida "lucha por la justicia", y, en últimas, justificar — con argumentos del siglo $\mathrm{XVI}$ - las empresas coloniales europeas. Si en Las Casas hubo una lucha por la justicia, esta nunca fue una lucha abstracta, el mero reflejo de una ideología benévola que procedía de una tradición estoica y escolástica. Su obra, más que este tipo de argu- 
mentación, refleja una experiencia directa de un sistema de explotación cuyos rasgos de irracionalidad eran perceptibles y sus efectos devastadores más que evidentes. Por esto resulta absurdo atenerse a una mera apología de las "ideas de justicia" y desconocer, al mismo tiempo, todo el encadenamiento material que provocó la conquista. Con Las Casas, al menos, no es posible esta ambigüedad. Por eso resulta lógico que el mentor de todas las academias lo margine de la historia haciendo de él un paranoico ${ }^{\mathrm{B}}$.

B La referencia, por una cierta parquedad de las fuentes de que disponemos o por insuficiencia en nuestro conocimiento del contexto intelectual de esos años, permanece por ahora enigmática. ¿A qué hechos polémicos se refería Colmenares y cuál era el "el mentor de todas las academias", a quien el historiador señala como impulsor de la vieja idea de que las Casas era un "paranoico", como forma de deslegitimar la importancia de sus análisis? 